\title{
Congenital muscular dystrophy without intellectual disability
}

INSERM

\section{Source}

INSERM. (1999). Orphanet: an online rare disease and orphan drug data base. Congenital muscular dystrophy without intellectual disability. ORPHA:370980

Congenital muscular dystrophy without intellectual disability is a rare, genetic, cong enital muscular dystrophy due to dystrog lycanopathy disorder characterized by a wide phenotypic spectrum which includes hypotonia and muscular weakness present at birth or early infancy, delayed or arrested motor development, and normal intellectual abilities with normal (or only mild abnormalities) neuroimaging studies. Feeding difficulties, joint and spinal deformities, and respiratory insufficiency may be associated. Decreased alphadystroglycan on immunohistochemical muscle staining and elevated serum creatine kinase are observed. 